\title{
Training The Development of Tavagi Multimedia Based on Scientific Approach to Support 2013 Curriculum on Science Teachers in Rayon 1 Pasaman District
}

\author{
Hufri*, Silvi Yulia Sari \\ Jurusan Fisika, FMIPA Universitas Negeri Padang, Padang, 25131, Indonesia \\ *hufri_fis@fmipa.unp.ac.id
}

Diterima 22 Oktober 2019, Disetujui 26 November 2019, Dipublikasikan 30 November 2019

\begin{abstract}
This activity aims to improve the competence of science teachers at Rayon 1 Pasaman in developing scientific-based interactive multimedia to support the 2013 curriculum. The target to be achieved is to increase the competency of teachers in developing TAVAGI multimedia (Text, Audio, Video, Animation, Graph ,and Interactivity) based on scientific approach. To achieve the goals and targets set, the method used consists of the observation phase, the orientation and discussion phase, the preparation stage for implementation, the implementation phase, the monitoring and evaluation stage as well as the data analysis and report stage. The instrument used was a test on TAVAGI multimedia and an activity questionnaire. The results of data analysis of the pretest and posttest, obtained the average pretest score was 34.28 and the average posttest score was 44.77 . The data showed that posttest was higher than the pretest value. From the paired $t$ test, the significance results obtained $0,000<0.05$. So it can be concluded that the training activities have been able to increase the competence of the natural sciences teachers in Rayon 1 Pasaman in developing scientificbased interactive multimedia to support the 2013 curriculum. Based on the questionnaires about the implementation of the activity, which was given at the end of the training activity, the results were obtained that the participants stated that this activity was very useful and related to learning in school.
\end{abstract}

Keyword: TAVAGI Multimedia, Science.

This is an open access article distributed under the Creative Commons 4.0 Attribution License, which permits unrestricted use, distribution, and reproduction in any medium, provided the original work is properly cited. (C2017 by author and Universitas Negeri Padang.

\section{Pendahuluan}

Pendidikan di Kabupaten Pasaman khususnya pada mata pelajaran IPA, masih tertinggal jika dibandingkan dengan Kabupaten dan Kota lain di Sumatera Barat. Hal ini dapat dilihat dari hasil peringkat UN tahun 2018 yaitu berada pada peringkat 17 dari $19 \mathrm{Kota} /$ Kabupaten di Sumatera Barat, nilai rata rata komulatif 4 mata pelajaran adalah 48,05. Hal ini juga menyebabkan Indeks Pembangunan Manusia (IPM) di Kabupaten Pasaman juga rendah yaitu 64,94, dibandingkan Provinsi Sumatera Barat yaitu 71,24[1]. Berdasarkan observasi dan diskusi yang dilakukan dengan dengan beberapa guru dan kepala sekolah pada rayon 1 di Pasaman (MGMP guru-guru IPA di Pasaman di bagi atas tiga rayon, yaitu rayon $1 \mathrm{di}$
Simpati, rayon 2 di Lubuk Sikaping dan rayon 3 di Rao), dalam pembelajaran umumnya guru belum dapat mengembangkan bahan ajar sendiri dengan mengkaitkan materi tersebut dengan kondisi di sekitar siswa. Penggunaan multimedia dalam pembelajaran juga sangat jarang sekali.

Pembelajaran merupakan suatu proses kompleks, yang terjadi pada setiap orang sepanjang hidupnya. Belajar bukan hanya sekedar aktivitas yang sedang terjadi pada diri individu, namun terjadi atas usaha individu sendiri dengan cara mengolah informasi dan menerapkannya.

Selanjutnya sesuai dengan Permendikbud No 103 dalam pendekatan saintifik siswa diharapkan mampu berperan aktif dalam proses pembelajaran dengan mengamati, menanya, mencoba, manalar, lalu mengkomunikasikan apa yang telah 
didapatkan dengan menanamkan karakter pada setiap siswa sehingga tercipta siswa yang kreatif dan inovatif[2]. Hal ini juga sesuai dengan hasil penelitian oleh Hufri dkk[3] bahwa diperoleh hasil belajar siswa menjadi lebih baik, setelah menggunakan perangkat pembelajaran yang berbasiskan kontekstual pada pembelajaran quided inquiry.

\section{Solusi/Teknologi}

Media pembelajaran merupakan salah satu alternatif yang dapat digunakan untuk membantu siswa dalam mengatasi permasalahan pembelajaran tersebut. Jenis media pembelajaran yang bisa digunakan guru dalam proses pembelajaran tersebut antara lain adalah media interaktif. Media interak ini dapat mengaktifkan beberapa indera siswa secara bersamaan, yaitu penglihatan, pendengaran, dan sentuhan. Dimana akan memberi keuntungan bagi siswa dibandingkan dengan penyampaian hanya dengan penglihatan ataupun pendengaran.

Pembelajaran berbasis multimedia akan lebih menarik, tidak monoton, dan memudahkan penyampaian. Multimedia pembelajaran interaktif dapat dibuat berdasarkan kreatifitas guru dalam membelajarkan materi pembelajaran dengan memanfaatkan media yang ada. Sehingga pembelajaran yang dilakukan dapat mengembangkan potensi peserta didik agar memiliki kemampuan hidup sebagai pribadi dan warga negara yang beriman, produktif, kreatif, inovatif, dan afektif. Agar hal ini dapat dilakukan, maka peningkatan kompetensi guru harus selalu ditingkatkan.

Peningkatan kualitas pembelajaran dengan meningkatkan kemampuan guru ini juga telah dilakukan melalui pengembangan media pembelajaran pada guru-guru di Solok Selatan[4]. Pelatihan pengembangan multimedia berbasiskan kontekstual untuk pembelajaran inquiry bagi guruguru SMPN 19 dan SMPN 34 Kabupaten Solok Selatan[5]. Peningkatan kompetensi pedagogik guru-guru IPA SMP Solok Selatan melalui pendampingan implementasi pembelajaran kontekstual berdasarkan pendekatan saintifik[6] dan Peningkatan kemampuan guru-guru IPA Solok Selatan dalam mengembangkan mutimedia pembelajaran melalui penguasaan editing video[7].
Berdasarkan kondisi tersebut maka tim memberikan pelatihan pengembangan multimedia TAVAGI (Teks, Audio, Video, Animasi, Graph, and Interactive) berbasis saintifik untuk mendukung kurikulum 2013. Kegiatan ini merupakan upaya untuk meningkatkan kompetensi guru-guru, khususnya dalam multimedia pembelajaran. Program kemitraan ini sejalan dengan program yang dilakukan oleh dinas pendidikan Pemerintah Daerah Pasaman dalam meningkatkan kualitas pendidikan melaluipeningkatan kompetensi guru.

\section{Materi dan Metodologi}

\section{A. Materi}

Sesuai dengan tuntutan kurikulum 2013 bahwa pembelajaran ditujukan untuk mengembangkan potensi peserta didik agar memiliki kemampuan hidup sebagai pribadi dan warga negara yang beriman, produktif, kreatif, inovatif, dan afektif, serta mampu berkontribusi pada kehidupan masyarakat, berbangsa, bernegara, dan peradaban dunia. Untuk dapat melaksanakan pembelajaran sesuai dengan tuntutan kurikulum tersebut, maka diperlukan kemampuan dari guru untuk menciptakan kondisi agar dapat terjadi pembelajaran tersebut[8].

Pembelajaran membutuhkan kondisi atau suasana yang dapat membuat belajar lebih mudah, sederhana, bermakna dan menyenangkan agar siswa dapat menerima ide, gagasan, mudah memahami permasalahan dan pengetahuan sehingga dapat mengkonstruksi sendiri pengetahuan ya secara aktif, kreatif dan produktif.

Selanjutnya sesuai dengan Permendikbud pada pendekatan saintifik siswa diharapkan mampu berperan aktif dalam proses pembelajaran, usaha tersebut akan dapat tercapai jika semua komponen pembelajaran harus dipertimbangkan termasuk pembelajaran menggunakan multimedia pembelajaran. Jenis media pembelajaran yang bisa digunakan guru dalam proses pembelajaran tersebut antara lain adalah multimedia TAVAGI.

Multimedia TAVAGI ini dapat mengaktifkan beberapa indera siswa secara bersamaan, yaitu penglihatan, pendengaran, dan sentuhan. Hal ini akan memberi keuntungan bagi siswa dibandingkan dengan penyampaian hanya dengan penglihatan ataupun pendengaran. Jadi dengan 
mengamati, menanya, mencoba, manalar, dan mengkomunikasikannya, ini juga akan mengasilkan kemampuan dalam berfikir kritis dan kreatif pada siswa[9].

Sehingga dalam pembelajaran, peserta didik selalu didorong untuk belajar melalui keterlibatan aktif dengan keterampilan-keterampilan, konsepkonsep, dan prinsip-prinsip. Guru mendorong peserta didik untuk mendapatkan pengalaman dengan melakukan kegiatan yang memungkinkan mereka menemukan konsep dan prinsip-prinsip untuk diri mereka sendiri. Dengan kata lain, pembelajaran terjadi apabila peserta didik terlibat secara aktif dalam menggunakan proses mentalnya agar mereka memperoleh pengalaman, sehingga memungkinkan mereka untuk menemukan beberapa konsep atau prinsip tersebut.

Untuk itu dalam pembelajaran harus dilakukan perubahan dari pola pembelajaran satu arah (interaksi guru-peserta didik) menjadi pembelajaran interaktif (interaktif guru-peserta didik-masyarakat-lingkungan alam, sumber/media lainnya), pola pembelajaran pasif menjadi pembelajaran aktif-mencari (pembelajaran siswa aktif mencari semakin diperkuat dengan model pembelajaran dan pendekatan sains) dan pola pembelajaran alat tunggal menjadi pembelajaran berbasis alat multimedia.

Menurut Computer Technology Research menyatakan:

1. Manusia mampu mengingat $20 \%$ dari apa yang dia lihat.

2. Manusia mampu mengingat $30 \%$ dari apa yang dia dengar.

3. Manusia mampu mengingat $50 \%$ dari apa yang didengar dan dilihat.

4. Manusia mampu mengingat $80 \%$ dari apa yang didengar, dilihat, dan dilakukan

Dengan ini maka diharapkan siswa mampu memahami materi pembelajarannya secara maksimal dan mengembangkan kemampuan berfikir kreatif siswa tersebut. Kemapuan berfikir kreatif merupakan suatu proses berpikir untuk mengungkapkan hubungan-hubungan baru, melihat sesuatu dari sudut pandang baru dan membentuk kombinasi baru dari dua konsep atau lebih yang sudah dikuasai sebelumnya.

\section{B. Metodologi}

Metode yang digunakan untuk merealisasikan solusi yang diajukan untuk menyelesaikan masalah pada guru-guru IPA SMP Rayon 1 di Kabupaten Pasaman, maka pelaksanaan kegiatan PKM dilakukan melalui lima tahap. Tahapan yang dilaksanakan yaitu tahap orientasi dan diskusi, tahap persiapan pelaksanaan, tahap pelaksanaan, tahap monitoring dan evaluasi dan tahap analisis data dan pembuatan laporan.

Instrumen yang digunakan adalah tes tentang multimedia TAVAGI dan angket pelaksanaan kegiatan. Analisis data menggunaka uji $t$ berpasangan dan prosentase.

Secara rinci tahapan kegiatan, pelaksanaan kegiatan dapat dilihat pada Tabel 1.

Tabel 1. Tahap-Tahap Kegiatan dan Tempat pelaksanaannya

\begin{tabular}{|c|c|c|}
\hline $\begin{array}{l}\text { Tahapan } \\
\text { Kegiatan }\end{array}$ & $\begin{array}{c}\text { Jenis } \\
\text { Kegiatan }\end{array}$ & $\begin{array}{c}\text { Tempat } \\
\text { Pelaksanaan }\end{array}$ \\
\hline 1 & $\begin{array}{l}\text { Orientasi dan } \\
\text { Diskusi }\end{array}$ & $\begin{array}{l}\text { Laboratorium } \\
\text { Fisika UNP dan } \\
\text { Tempat Mitra }\end{array}$ \\
\hline 2 & $\begin{array}{l}\text { Tahapan } \\
\text { persiapan } \\
\text { pelaksanaan }\end{array}$ & $\begin{array}{l}\text { Laboratorium } \\
\text { Fisika UNP dan } \\
\text { Tempat Mitra }\end{array}$ \\
\hline 3 & $\begin{array}{l}\text { Tahapan } \\
\text { pelaksanaan }\end{array}$ & (Tempat Mitra) \\
\hline 4 & $\begin{array}{l}\text { Tahapan } \\
\text { monitoring } \\
\text { dan evaluasi }\end{array}$ & (Tempat Mitra) \\
\hline 5 & $\begin{array}{l}\text { Analisis data } \\
\text { dan } \\
\text { pembuatan } \\
\text { laporan }\end{array}$ & $\begin{array}{l}\text { Laboratorium } \\
\text { Fisika UNP }\end{array}$ \\
\hline
\end{tabular}

\section{Hasil dan Diskusi}

\section{A. Hasil}

Sesuai dengan tujuan PKM ini, pertama memberikan pengetahuan secara teoritis tentang pengembangan multimedia TAVAGI, dengan menggunakan fakta yang dekat dengan kehidupan sehari-hari siswa sehingga dapat memfasilitasi siswa dalam pembelajarannya. Ke dua melakukan diskusi dan pembimbingan pengembangan 
multimedia TAVAGI berbasikan berbasiskan saintifik untuk mendukung kurikulum 2013.

Berdasarkan data hasil pretest dan postest dari guru-guru yang melaksanakan pretest dan postest (yang mengumpulkan lembaran jawaban) kedua test. Pengujian menggunakan SPSS 20, diperoleh deskripsi dari kedua data seperti pada Tabel 2

Tabel 2. Descriptive Statistics

\begin{tabular}{lccccc}
\hline & & & \multicolumn{2}{c}{ Std. } & Minimu \\
& N & Mean & $\begin{array}{c}\text { Deviat } \\
\text { ion }\end{array}$ & $\begin{array}{c}\text { Maxim } \\
\text { um }\end{array}$ \\
& & & & \\
\hline Pretest & 21 & 34.28 & 12.35 & 13.30 & 66.70 \\
postest & 21 & 44.77 & 10.78 & 26.70 & 66.70 \\
\hline
\end{tabular}

Dari Tabel 2. bahwa nilai pretest rata-rata adalah 34,28 dengan nilai minimum adalah 13,30 dan nilai maksimum 66,70 . Nilai posttest rata-rata adalah 44,77 dengan nilai minimum adalah 26,70 dan nilai maksimum 66,70. Jadi nilai rata-rata, postest lebih tinggi dibandingkan dengan nilai pretest.

Untuk membandingkan hasil ujian pretest dengan hasil postest dari peserta maka terlebih dahulu dilakukan uji normalitas data. Hasil normalitas data dapat dilihat pada Tabel 3.

Tabel 3. Hasil Uji Normalitas Data

\begin{tabular}{lrrr}
\hline & \multicolumn{3}{c}{ Shapiro-Wilk } \\
\cline { 2 - 4 } & Statistic & df & \multicolumn{1}{l}{ Sig. } \\
\hline Pretest & .941 & 21 & .229 \\
Postest & .913 & 21 & .064 \\
\hline
\end{tabular}

Berdasarkan hasil analisis pada Tabel 3 diperoleh hasil pretest dengan signifikasi 0,229 > 0,05 kelompok data berdistribusi normal dan untuk data postest dengan signifikansi 0,064 > 0,05 data juga berdistribusi normal. Selanjutnya dilakukan uji homogenitas seperti pada Tabel 4.

Table 4. Test of Homogenity of Variances

\begin{tabular}{rrrrr}
\hline $\begin{array}{c}\text { Levene } \\
\text { Statistic }\end{array}$ & $\mathrm{df}_{1}$ & $\mathrm{df2}$ & \multicolumn{1}{l}{ Sig. } \\
\hline .096 & 1 & 40 & .758 \\
\hline
\end{tabular}

Dari Tabel 4, diperoleh nilai signifikansi 0,758 > 0,05 yang berarti data adalah homogen.

Selanjutnya untuk melihat perbedaan dari hasil pretes terhadap postes dilakukan dilakukan uji $\mathrm{t}$ berpasangan. Hasil analisis dapat dilihat pada Tabel 5.

Tabel 5. Paired Samples Test

t df Sig. (2-tailed)

\begin{tabular}{lccc}
\hline Pair 1 $\begin{array}{c}\text { Pretest - } \\
\text { Postest }\end{array}$ & 21.782 & .000 \\
\hline
\end{tabular}

Tabel 5. Menunjukkan hasil signifikansi $0,000<$ 0,05, Jadi dapat diambil kesimpulan bahwa terdapat perbedaan antara hasil pretes dengan postes. Dimana nilai rata-rata postest lebih tinggi dari nilai rata-rata pretest Tabel 2, ini menunjukkan bahwa terdapat peningkatan kompetensi guru-guru dalam pengembangan multimedia TAVAGI berbasiskan saintifik untuk mendukung kurikulum 2013. Seperti terlihat pada Gambar 3.

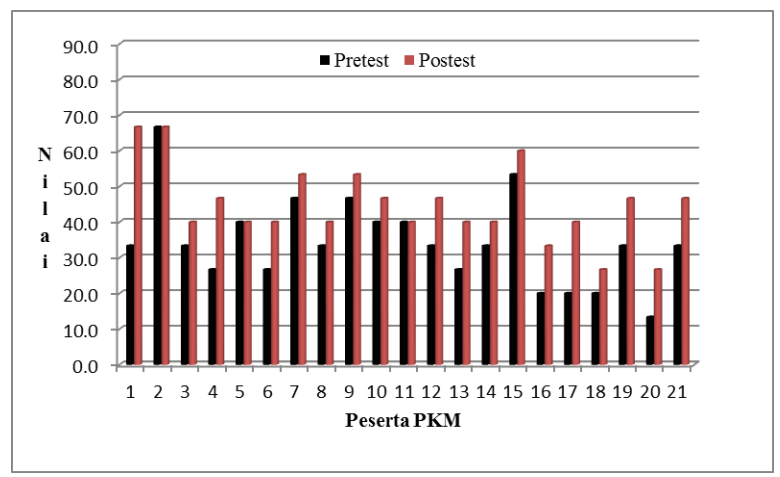

Gambar 1. Nilai Pretest dan Postest

Berdasarkan hasil angket tentang respon peserta terhadap kegiatan PKM, semua peserta menyatakan kegiatan pelatihan ini dapat meningkatkan kompetensi guru, sehingga akan dapat membuat setiap peserta didik berpartisipasi aktif dalam proses pembelajaran.

\section{B. Pembahasan}

Dari analisis data hasil pretest dan hasil postest, diperoleh peningkatan nilai rata-rata dari pretest yaitu 34,28 menjadi 44,77 pada postest. Jadi nilai rata-rata, postest lebih tinggi dibandingkan dengan nilai 
pretest. Dari uji paired $t$ test, diperoleh hasil signifikansi $0,000<0,05$, dengan demikian dapat disimpulkan bahwa terdapat peningkatan kompetensi guru-guru dalam pengembangan multimedia TAVAGI berbasiskan saintifik untuk mendukung kurikulum 2013.

Foto-foto kegiatan PKM yaitu :

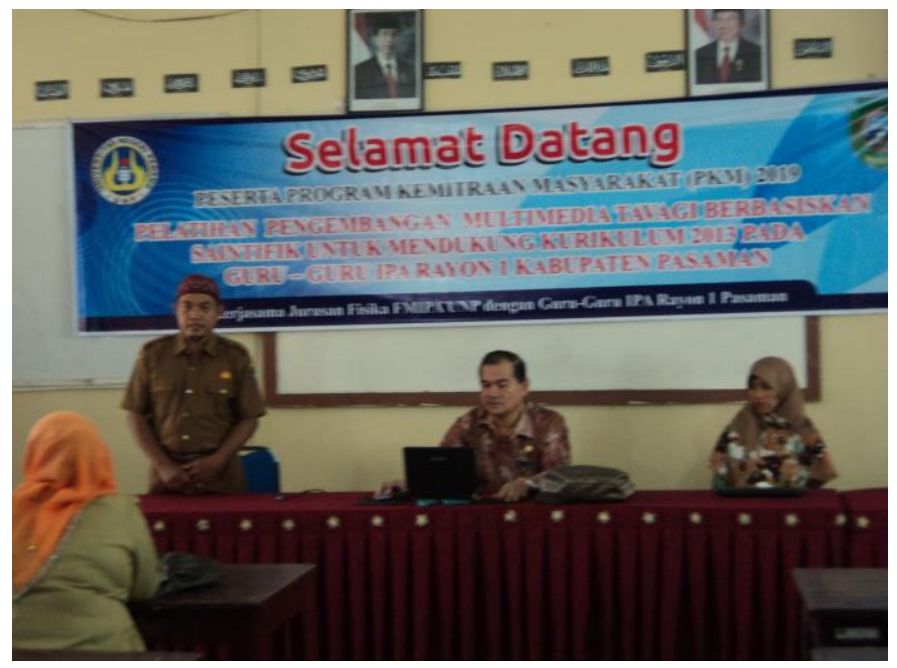

Gambar4. Bpk Ketua MGMP IPA rayon 1

Pasaman memberikan sambutan pembukaan pelatihan kepada Guru-Guru

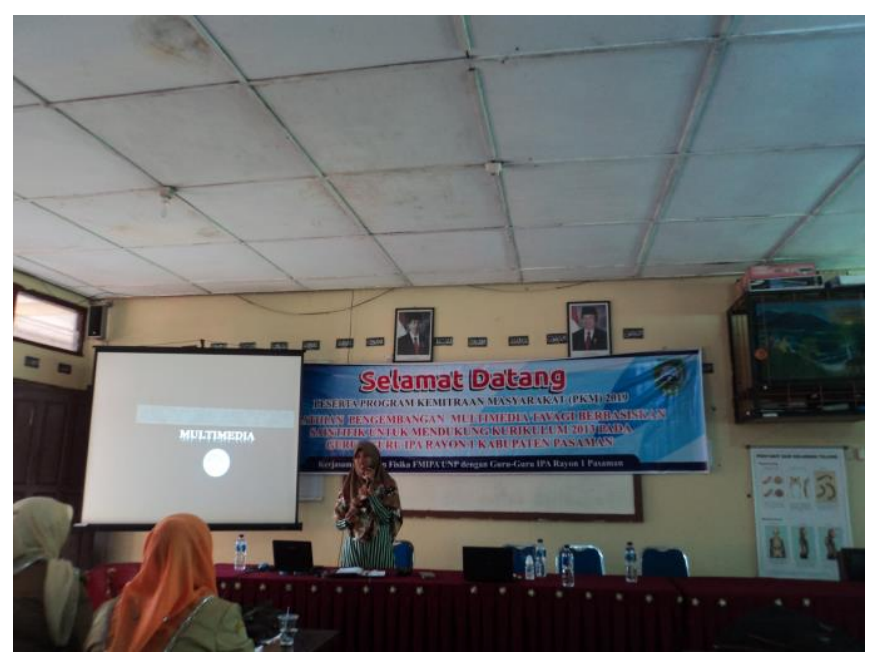

Gambar 5. TIM PKM sedang memberikan materi pelatihan kepada Guru-Guru SMPN Pasaman

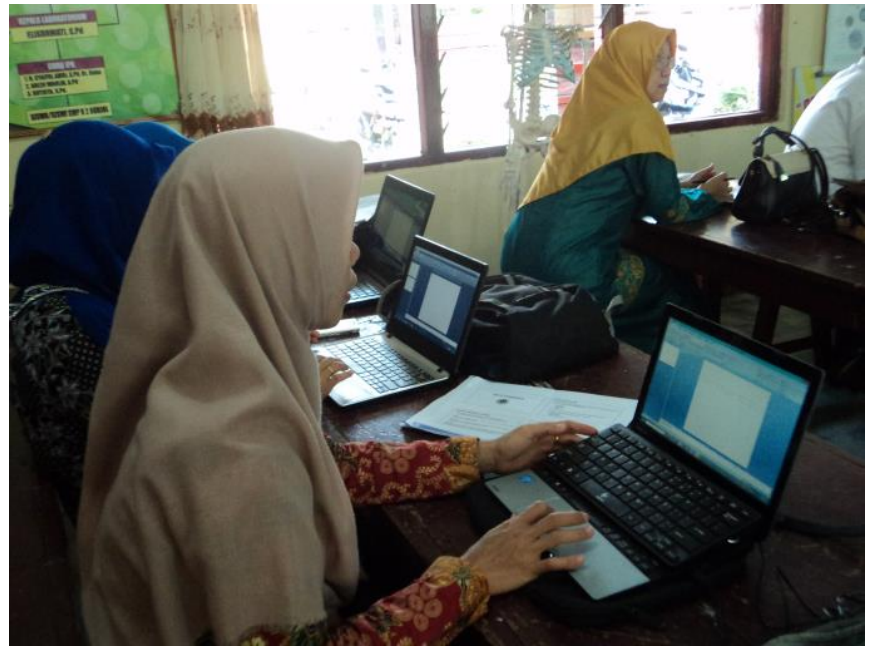

Gambar 6. Peserta serius mencoba merancang multimedia

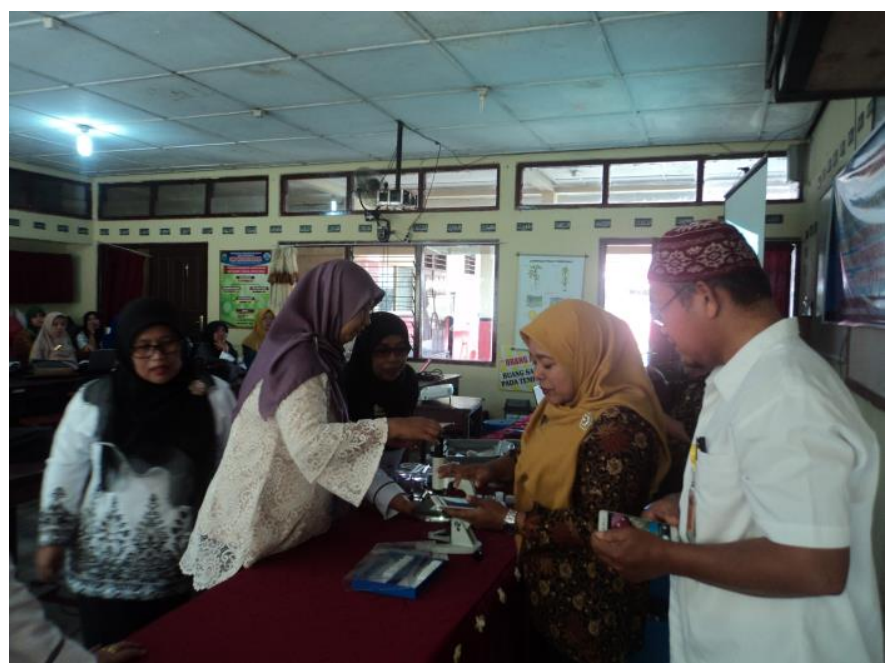

Gambar 7. Tim PKM mendampingi peserta dalam pembuatan multimedia

\section{Kesimpulan}

Berdasarkan analisis dari hasil evaluasi yang telah dilakukan sampai tahap yang dilakukan dapat diambil beberapa kesimpulan :

1. Materi kegiatan PKM dapat meningkatkan kompetensi guru-guru dalam pengembangan multimedia TAVAGI berbasiskan saintifik untuk mendukung kurikulum 2013ru.

2. Kegiatan pelatihan ini juga sudah menghasilkan multimedia yang digunakan guru dalam kegiatan pembelajarannya 


\section{Ucapan Terima Kasih}

Terima kasih kami sampaikan kepada Rektor UNP dan Ketua LP2M UNP yang telah telah mendanai kegiatan PKM ini melalui dana PNBP tahun 2019.

\section{Pustaka}

[1] http://npd.data.kemdikbud.go.id/file/pd. (diakses 25 Maret 2019)

[2] Permendikbud, 2013. No. 70 Tahun 2013 Kerangka Dasar dan Struktur Kurikulum Jakarta: Kementerian Pendidikan dan Kebudayaan.

[3] Hufri, (2017), Pengembangan Bahan Ajar Fisika Berbasiskan Kontekstual Pada Pembelajaran Quided Inquiry Untuk Kelas XI SMA/MA, Prosiding Semirata 2017 Bidang MIPA BKS-PTN Wilayah Barat 2. Universitas Jambi, hal. 1312-1321

[4] Hufri, Harman Amir, Mona TC, Silvia I, Naimis S H. (2018). Peningkatan Kompetensi Guru-Guru SMP_Solok Selatan Melalui Pelatihan Pengembangan Media Pembelajaran Berbasis Kontekstual Dengan Pendekatan Saintifik. Pelita Eksakta 1 (vol 1), 37-42

[5] Sari Silvi Yulia, Hufri, Wahyuni Satria Dewi, 2018, Pelatihan Pengembangan Multimedia Berbasiskan Kontekstual Untuk Pembelajaran Inquiry Bagi Guru-Guru SMPN 19 dan SMPN 34 Kabupaten Solok Selatan, Pelita Eksakta 1 (vol 2), 102-107

[6] Hufri, Letmi D, Harman A, (2018). Peningkatan Kompetensi Pedagogik GuruGuru IPA SMP Solok Selatan Melalui Pendampingan Implementasi Pembelajaran Kontekstual Berdasarkan Pendekatan Saintifik, Pelita Eksakta 1 (vol 2), 108-112

[7] Hufri, Silvi Y S, Naimis S H, Silvia I, (2019). Improvement of Teacher Capability in Solok Selatan District in Developing Multimedia Through Training Video Editing, Pelita Eksakta 2 (vol 1), 41-47

[8] Permendikbud, 2013. No. 70 Tahun 2013 Kerangka Dasar dan Struktur Kurikulum Jakarta: Kementerian Pendidikan dan Kebudayaan.

[9] Elmande, Yusuf. 2014. Modul Komunikasi multimedia. Jakarta: Universitas Mercu Buana. 